\title{
Effect of pass schedule and groove design on the metal deformation of $38 M n V S 6$ in the initial passes of hot rolling
}

\author{
R S NALAWADE*, V R MARJE, G BALACHANDRAN and V BALASUBRAMANIAN \\ Kalyani Carpenter Special Steel Pvt. Ltd., Mundhwa, Pune 411036, India \\ e-mail: rahul.nalawade@kcssl.com; vishal.marje@kcssl.com; dr.gbalachandran@kcssl.com; bala@kcssl.com
}

MS received 29 October 2014; revised 9 June 2015; accepted 1 September 2015

\begin{abstract}
The deformation behaviour of a hot rolled micro-alloyed steel bar of grade 38MnVS6 was examined using an FEM model during the initial passes in a blooming mill, as a function of three different pass schedules, roll groove depth, collar taper angle and corner radius. The simulations predicted the effective strain penetration, load, torque, fish tail billet end shapes, and metal flow behaviour at a chosen temperature, mill rpm and draft. The model predictions were validated for typical groove geometry and a typical pass schedule. Lower collar taper angle, lower corner radius and higher depth of groove in hot rolling enabled achievement of higher strain penetration, higher mill load and lower fish tail formation. The present study establishes the capability of the model to improve the internal quality of the rolled billet as measured by effective strain which was corroborated to the rolled bar macrostructure and microstructure. The model enables yield improvement by the choice of draft to minimise fish tail losses. The surface quality is improved by the ability to avoid fin formation that occurs at certain conditions of rolling. Thus, the groove geometry, roll pass schedule and rolling mill parameters and temperature can be optimised for best product quality and yield.
\end{abstract}

Keywords. Hot rolling; groove geometry; pass design; rolling load; FEM simulation.

\section{Introduction}

The quality and productivity of hot rolled bar steel products strongly depends on hot rolling parameters such as strain, strain rate, temperature, groove design and rolling sequence. It influences the metal deformation behaviour within the pass and mill load requirement apart from roll wear. The metal flow behaviour in a hot rolling process is a complex phenomenon, which is complicated due to tensorial stress distribution that is influenced by the material properties and deformation parameters. The knowledge of the in-process deformation and microstructural changes is critical for the optimisation of the pass design, the pass schedule and ultimately, the properties of the as rolled product. Computer based FEM simulations incorporating deformation models can be used to develop optimum process sequences to obtain steels with sound quality, desirable microstructure and mechanical properties by controlling the hot rolling process parameters.

In the hot rolling of bars, the material characteristics, rolling load, angle of bite, the roll groove geometry and roll pass sequence are reported to influence metal deformation and properties [1]. Using FEM based model on a rigid-plastic and slightly compressible material, the velocity field during the isothermal steady and unsteady plane

${ }^{*}$ For correspondence strain rolling condition was investigated and correlated the front and back end shapes [2]. Heavier reductions in the initial passes during ensured better void closure, cast structure break down, minimisation of fish tail and grain refinement $[3,4]$. In an FEM model for the deformation of an aluminium alloy, predictions of temperature, the front and the tail end deformation were closely matched with experimental values, although the flow stress values showed variation depending on the choice of constitutive equations used for thermo-mechanical deformation namely, hyperbolic sine method, Hensel and Spittel model and Norton Hoff models [5]. Using a coupled thermo-mechanical and empirical models, prediction of geometric parameters such as spread, cross sectional area, plastic strain and rolling force was determined and experimentally validated for the hot rolling of an aluminium alloy [6]. A 3D-thermo mechanical coupled FEM elasto-plastic model was applied for the prediction of stress, strain, temperature, rolling force and torque for the two-pass and four pass roll schedules in the continuous hot rolling of a large diameter mandrel bar [7]. A largedeformation constitutive model to evaluate roll force and torque in heavy-reduction was found to be in agreement with Misaka-Yoshimoto model for dynamic recrystallization [8]. A variation in the rolling load was predicted as a result of non-uniform heating of the slab, in a grooved bar rolling using an FEM model, which was validated by experiments [9]. The strength of rolled flat bar material has 
been improved by varying the accelerated cooling rate during rolling using FEM simulation technic [10]. The influence of the bloom geometry, friction coefficient, temperature and the degree of reduction in hot rolling was input in a thermomechanical model where the metal deformation could be correlated with the product integrity and mechanical properties [11]. Bar rolling with a revised pass design and modified friction coefficient was simulated using an FEM based deformation model which predicted experimental deformation [12]. The bloom geometry and rolling parameters such as rolling speed, temperature, friction coefficient on the stress-strain state of the system during rolling was optimised using FEM based model that enabled improvement of product mechanical properties [13]. The prediction of stress and strain field using rigid plastic finite element model could be assessed and the reliability was established with published literature [14]. Using a reverse material tracking FEM simulation technique, the end shapes of rolled bloom were predicted which enabled reduction in the end crop losses due to fishtail formation [15]. The modification of the initial preform to be rolled with convex end shapes minimised fish tail in hot rolling [16]. Using a non-linear finite element method a new flat-oval groove with a multi-direction low temperature deformation was proposed for ultra-fine grain development [17]. Using a FEM based simulation on hot deformation of steel prediction of load, torque, temperature distribution, metal flow behaviour, macrostructure, microstructure and austenitic grain size was validated with experimental data [18]. Roll pass design developed by analytical method was further optimised by FEM based model in a round bar rolling and in an oval-round roll pass and a combination of flat and round pass [19].

A typical roller of a blooming mill has different roll grooves in a single roll set depending upon the products produced as typically shown in figure 1(a). In every groove, the geometrical parameters such as collar taper angle, groove width, groove depth and corner radii (figure 1(b)), plays an important role in influencing the metal deformation. Appropriate design of these parameters enhances the capabilities of the mill to be exploited for achieving the best metallurgical quality and material yield.

The effects of groove geometric parameters that needs optimisation are collar taper angle, groove depth and groove corner radius on deformation have been discussed [20]. The collar taper angle in the roll groove influences the strain penetration, roll wear and the mill load. Very low collar angle restricts the metal flow within the pass which results in higher friction, higher mill load and wear of the rolls. Very high collar angle on the other hand, results in under-filling of pass. The groove depth influences the strain achievable during rolling. High groove depths result in a higher contact area of the rolling stock with the roll, which results in higher heat losses and higher friction. The restriction of the width in a deeper groove results in a better core strain in the bar. Smaller groove depth leads to off-square rolling with higher load. The groove corner radius influences the metal flow behaviour and mill capacity. High corner radius results in under filling due to higher spread requirements especially at lower drafts. At lower collar angles, bloom corner is colder compared to face as higher heat transfer takes place due to the corner contacting the groove bottom and side walls. Sharp corners in addition increase friction and poor metal flow. So, the design of the roll groove geometry and the roll pass sequence are important aspect to be assessed. The prediction of the load and torque with different groove designs plays an important role in order to improve the draft during rolling.

The roll grooves in a roller and the roll pass sequence in a hot rolling mill are usually designed based on the type of grades and dimensions of the products and the mill capacity. These have been established over the years based on analytical methods. With modern capability of computer based simulation of the hot deformation process, it is possible to evolve roll groove and pass design in a more predictable

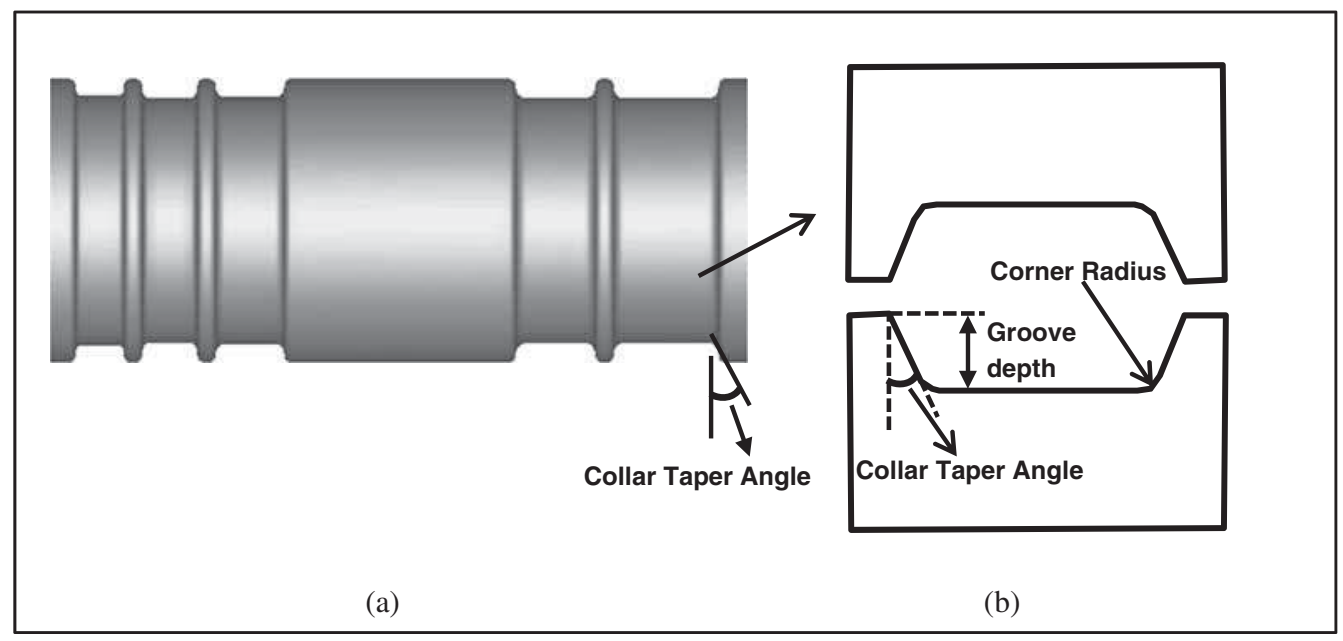

Figure 1. (a) Blooming mill grooved roller with different groove sizes to achieve required product dimensions. (b) Typical roll groove geometry of importance during hot rolling. 
manner. The metal deformation behaviour within the given rolls can be correlated to the chosen pass design and rolling parameters.

In this study, the effect of metal flow behaviour in a single groove with variation of groove geometry and pass sequence designs has been studied for the initial few passes in detail, using a finite element based deformation model in a reversible two high rolling mill. Literature review shows that hardly simulations are there which have studied the influence of groove geometry on metal flow behaviour on internal metal quality at the blooming mill stage. The present model assesses the parameters such as temperature distribution, strain penetration, fishtail formation, microstructure rolling load, torque, in the hot rolling of a typical micro alloyed steel grade. Micro-alloyed steels are an important grade produced in significant quantities by the company for a wide variety of automotive end users. This grade is sensitive to thermomechanical processing and the ability to observe the deformation behaviour in hot rolling is of interest.

\section{FEM model}

In the present work, FEM based FORGE simulation software is used to study the metal flow behaviour in the hot rolling process. The rolls are considered as rigid objects while the metal deformed is plastic. The elastic effect is neglected for bloom. The model uses purely visco-plastic approximations. The constitutive equations of the metal flow behaviour at a given temperature, deformation load, friction and the geometry are based on 3D isotropic visco-plastic behaviour of Norton Hoff law (Eq. 1);

$$
S=2 K\left(\sqrt{3} \dot{\varepsilon}_{e q}\right)^{m-1} \dot{\varepsilon}_{v p},
$$

where s - Deviatoric stress tensor, $\dot{\varepsilon}_{e q}-$ Equivalent strain rate, $\dot{\varepsilon}_{v p}$ - Viscoplastic strain rate, $\mathrm{K}, \mathrm{m}$ - material parameters.

The mechanical law (Eq. 2) used in the model is isotropic with an additive decomposition of the strain rate:

$$
\dot{\varepsilon}_{e q}=\dot{\varepsilon}^{e}+\dot{\varepsilon}^{p}
$$

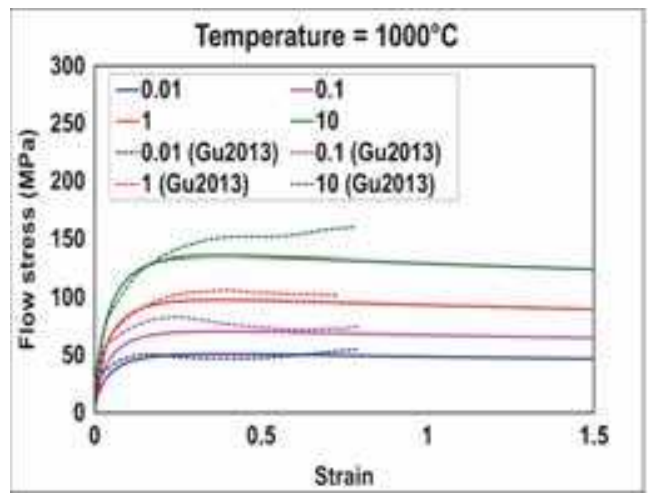

where $\dot{\varepsilon}^{e}$ is the elastic strain rate and $\dot{\varepsilon}^{p}$ the plastic or visco plastic strain rate.

The plastic law (Eq. 3) is expressed by a Power law:

$$
\dot{\varepsilon}^{p}=\frac{1}{K}\left[\frac{\bar{\sigma}-R}{K}\right]^{\frac{1}{m}-1} \grave{\sigma},
$$

where $\sigma^{\prime}$ is the deviatoric stress tensor, $\bar{\sigma}$ is the usual equivalent stress, $K$ is the consistency constant and $m$ is the strain rate sensitivity.

The flow stress at elevated temperature at different strain and strain rates is evaluated by Hensel-Spittel model (Eq. 4) [24]. It is temperature dependent and takes strain hardening or softening behaviour into account.

$$
\sigma_{f}=A e^{m_{1} T} T^{m_{9}} \varepsilon^{m_{2}} e^{\frac{m_{4}}{\varepsilon}}(1+\varepsilon)^{m_{5} T} e^{m_{7} \varepsilon} \dot{\varepsilon}^{m_{3}} \dot{\varepsilon}^{m_{8} T}
$$

where $\sigma_{f}$ is flow stress, $\varepsilon$ is equivalent strain, $\dot{\varepsilon}$ is strain rate, $T$ is temperature given in Celsius, $m_{1}$ and $m_{9}$ define the material's sensitivity to temperature, $m_{5}$ term coupling temperature and strain, $m_{8}$ term coupling temperature and strain rate, $m_{2}, m_{4}$, and $m_{7}$ define the material's sensitivity to strain, $m_{3}$ depends on the material's sensitivity to the strain rate. These constants for the material under study were taken as an output from JMAT Pro software. The values of constants in Hensel Spittel flow stress equation are $A=1809.2421, m_{1}=-0.0029, m_{2}=-0.14227, m_{3}=$ $0.14102, m_{4}=-0.05764, m_{5}=0, m_{6}=0, m_{7}=0, m_{8}=0$, $m_{9}=0$. In order to cross check the correctness of these values, the flow stress calculated based on the Hensel Spittel equation at various strain rates as shown in figure 2 was compared with the flow stress values published [23] where good correlation could be established.

The thermal history during the hot rolling process is obtained by the general heat equation (Eq. 5) which considers internal heat generation parameter,

$$
\rho c=\frac{d T}{d t}=\operatorname{div}(\operatorname{kgrad}(T))+\dot{q}_{v}
$$

The input boundary conditions as in figure 3 are imposed in the model as per following equations:

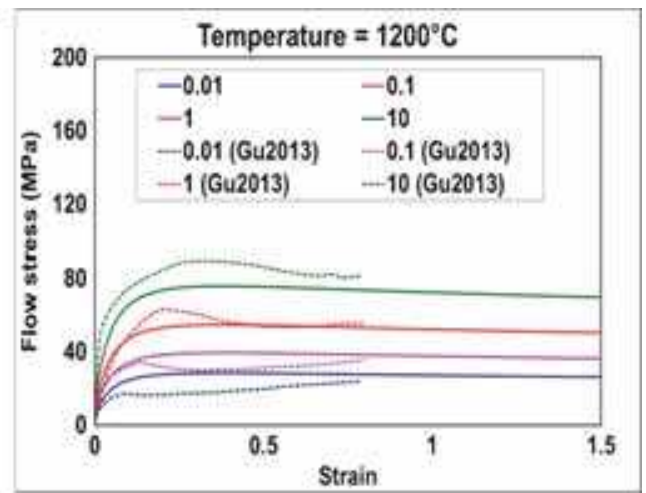

Figure 2. Comparison of the flow stress values of literature and predicted by Hensel Spittel equation at various temperature. 


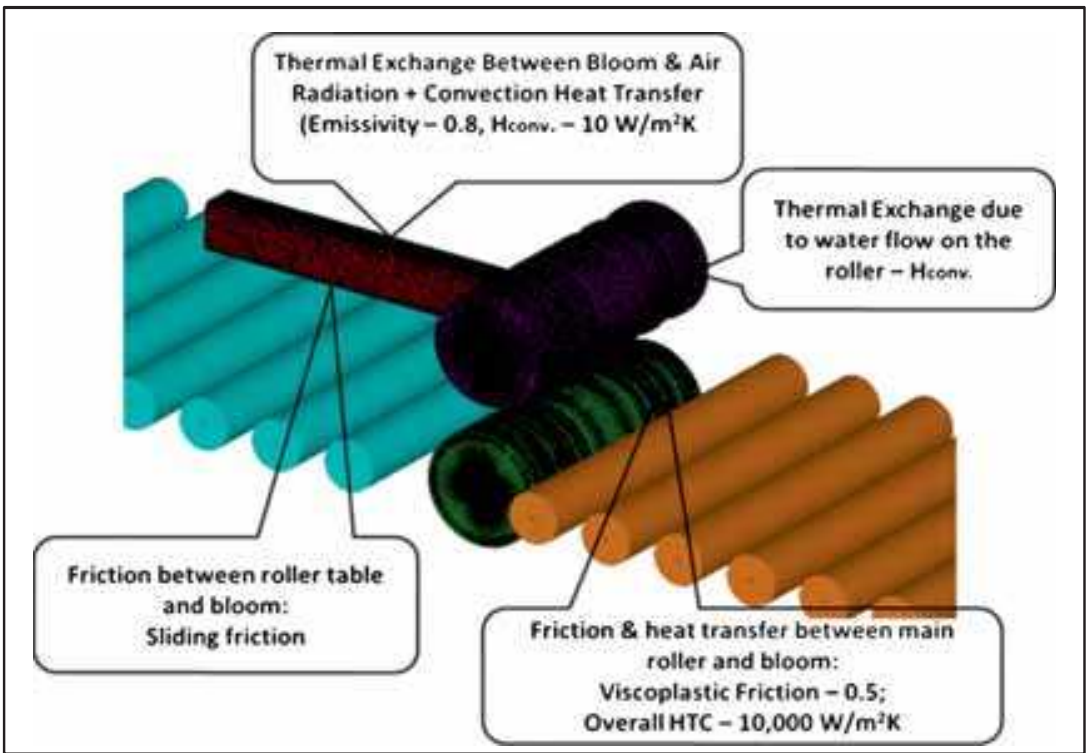

Figure 3. Different boundary conditions used during the rolling simulation.

The heat transfer due to convection with water cooling of rollers was taken into account by the input of a variable heat transfer coefficients along the length of the bloom as shown in figure 4 . The heat transfer due to surface radiation is defined by the following equation:

$$
-k \frac{d T}{d t}=\varepsilon_{r} \sigma_{r}\left(T^{4}-T_{\text {ext }}^{4}\right)
$$

where $\varepsilon_{r}$ is the emissivity, $\sigma_{r}$ is the Stefan's constant, and $T_{\text {ext }}$ is outside temperature. The heat transfer with the roller is given by the following equation:

$$
\varphi=\operatorname{kgrad}(T)=\alpha\left(T-T_{\text {ext }}\right),
$$

where $\alpha$ is heat transfer coefficient.

At the interface between part and tool the friction shear stress can be modelled by a "Viscoplastic Coulomb" law (Eq. 8) as used by Duan et al [5].

$$
\tau=\frac{-\alpha_{f}\left|\sigma_{n}\right| \Delta V}{|\Delta V|^{1-p}}
$$

where $\alpha_{f}$ is the friction coefficient.

The friction between the roll and the bloom surface depends upon the amount of reduction, temperature, surface roughness of the rollers and rolling velocity. Based on the Batchinov friction equation [8], a friction coefficient of 0.5 was used in the present model.

A Johnson-Mehl Avrami law is used to compute the fraction of ferrite, pearlite or bainite transformed

$$
y=y_{\max }\left(1-e^{-b t^{n}}\right),
$$

where $y$ is the transformed fraction for each phase and $y_{\max }$ is the maximum phase fraction which can be transformed

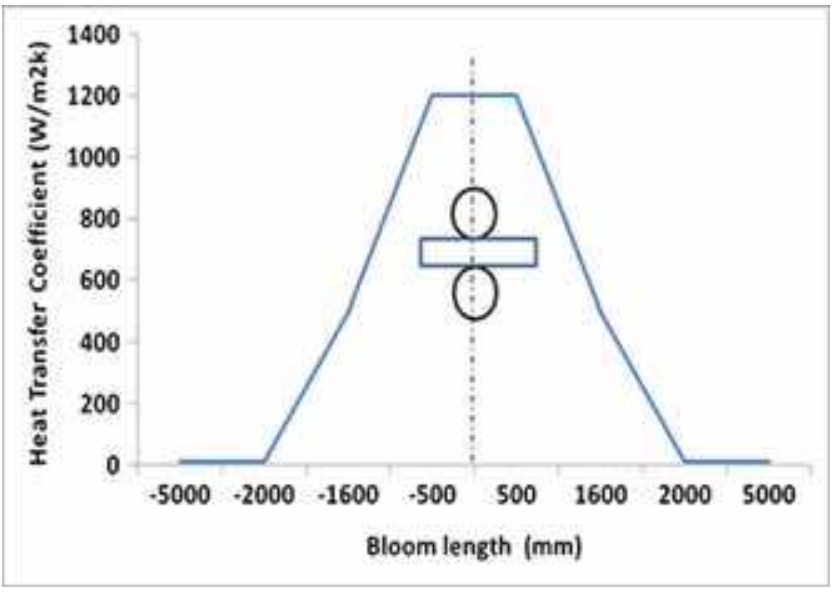

Figure 4. Variable heat transfer coefficients for convective heat transfer to take into account of effect of water splashes on rolls.

function of the temperature; $t$ is the elapsed time since the growth began; $B$ and $n$ are the Avrami law coefficients.

During the simulation that involves very large deformation, some elements become much more distorted and are not appropriate for further computation. Hence the model has the ability to regenerate the mesh several times in order to complete the simulation. Use of 3D tetrahedral elements with $20 \mathrm{~mm}$ mesh size is made. The tetrahedral mesh is found to suit the complex shapes in deformation and for automatic meshing and remeshing. The FEM mesh of the bloom consisted of 18300 nodes and 83973 elements. The rollers are considered as rigid body and meshed in 2D. The simulation was run on a - 64GB RAM and 8 cores server.

In the present work, the rolling mill roll configuration and the bloom were modelled using the Solid Edge software. The input parameters are given in table 1. In the present study, 
Table 1. Input parameters used for deformation simulation.

\begin{tabular}{ll}
\hline Bloom cross section & $320 \times 400 \mathrm{~mm}^{2}$ \\
\hline Bloom length & $3,480 \mathrm{~mm}$ \\
Input bloom temperature & $1,235^{\circ} \mathrm{C}$ \\
Initial temperature of rollers & $65^{\circ} \mathrm{C}$ \\
Roller Dia. & $925 \mathrm{~mm}$ \\
Rolling speed & $60 \mathrm{RPM}$ \\
Heat transfer coefficient in air $\left(\mathrm{W} / \mathrm{m}^{2} \mathrm{~K}\right)$ & 10 \\
Heat transfer coefficient in deformation $\left(\mathrm{W} / \mathrm{m}^{2} \mathrm{~K}\right)$ & 10,000 \\
Coefficient of friction & 0.5 \\
\hline
\end{tabular}

an initial bloom size of $320 \times 400 \mathrm{~mm}^{2}$ cross section with material properties of steel 38MnVS6 grade has been considered. The chemical composition is $0.38 \% \mathrm{C}, 1.4 \% \mathrm{Mn}$, $0.53 \% \mathrm{Si}, 0.014 \% \mathrm{P}, 0.16 \% \mathrm{Cr}, 0.09 \% \mathrm{~V}, 0.07 \% \mathrm{Ti}, 0.04 \%$ $\mathrm{Cu}$. To define the material grade, the physical properties and flow stress data at elevated temperature are incorporated in the simulation. The values of physical properties are specific heat $=778 \mathrm{~J} / \mathrm{kg}-\mathrm{K}$, density $=7850 \mathrm{~kg} / \mathrm{m}^{3}$, conductivity $=$ $35 \mathrm{~W} / \mathrm{m}-\mathrm{K}$. The initial rolling temperature was $1,235^{\circ} \mathrm{C}$ as per experimental observation With the above common input parameters and boundary condition, the metal deformation behaviour simulated at various designs of the initial stages of roll pass schedules and roll grooves are described below.

\subsection{Simulation on metal flow at varying initial pass schedule during hot rolling}

The simulation was attempted for only the initial few passes of the blooming mill. Three roll pass schedules (a), (b) and (c) were chosen as shown in table 2 . These pass schedules were designed in order to understand the effect of deformation strain per pass and pass sequence strategy on the metal flow behaviour. The pass schedule (a) consisted of lighter reduction per pass with overall deformation strain of $31 \%$ after four roughing passes. Pass schedule (b) has only one forward pass with $18 \%$ strain followed by reverse pass with $7 \%$ strain without tilt and ends with $24 \%$ overall deformation strain. In this case, higher width spread was possible during forward pass while due to pass filling reverse draft is lower to get a product free of fin formation. The pass schedule (c) has a forward pass of $18 \%$ strain followed by a $90^{\circ}$ tilt followed by a reverse pass of $19 \%$ strain, with an overall deformation strain of $32.5 \%$.

\subsection{Simulation on metal flow at varied roll groove geometry}

The present study examines the influence of collar taper angle with the pass schedule (a) in table 2 on metal deformation behaviour at various conditions. The collar taper angles considered were $9^{\circ}, 15^{\circ}, 25^{\circ}$ and $35^{\circ}$ (figure 1) The effect of roll groove depth on metal flow behaviour was studied for a
Table 2. Three types of pass schedules used during hot rolling.

\begin{tabular}{|c|c|c|c|}
\hline Pass no. & $\begin{array}{c}\text { Deformation strain } \\
\text { per pass }\end{array}$ & $\begin{array}{l}\text { Overall deformation } \\
\text { strain }\end{array}$ & $\begin{array}{l}\text { Reduction } \\
\quad \text { ratio }\end{array}$ \\
\hline \multicolumn{4}{|c|}{ Pass schedule (a) } \\
\hline Forward 1 & 13 & 13 & 1.15 \\
\hline Reverse 2 & 5 & 14 & 1.16 \\
\hline \multicolumn{4}{|l|}{$90^{\circ}$ tilt } \\
\hline Forward 3 & 10 & 24 & 1.31 \\
\hline Reverse 4 & 9 & 31 & 1.45 \\
\hline \multicolumn{4}{|c|}{ Pass schedule (b) } \\
\hline Forward 1 & 18 & 18 & 1.21 \\
\hline Reverse 2 & 7.5 & 24 & 1.31 \\
\hline \multicolumn{4}{|c|}{ Pass schedule (c) } \\
\hline Forward 1 & 18 & 18 & 1.21 \\
\hline \multicolumn{4}{|l|}{$90^{\circ}$ tilt } \\
\hline Reverse 2 & 19 & 32.5 & 1.48 \\
\hline
\end{tabular}

Note: $\%$ Reduction per pass $=($ area at input of pass - area after the pass $) \times$ $100 /$ ( area at input of pass).

$\%$ Overall deformation strain $=($ Initial bloom area - area after pass $) \times$ 100/(Initial bloom area).

Reduction ratio $=$ Initial bloom area/area after pass

Area implies cross section area.

single pass with a constant draft of $80 \mathrm{~mm}$ at groove depths of $50 \mathrm{~mm}, 63 \mathrm{~mm}$ and $80 \mathrm{~mm}$. The effect of corner radius of the rolling groove on the metal flow was simulated for a pass schedule (a) in table 2 at three different corner radiuses of R-15 mm, R-30 mm and R-45 mm

\section{Experimental validation on simulation trials}

The simulation results were validated by experimental studies on one typical roll groove geometry in the two-high reversible hot rolling mill. The experimental study was conducted using the similar input parameter as in table 1 . The experiments validated the rolling load torque, macrostructure and microstructure during hot rolling. The experimental validation was done with a pass schedule (a) using a roll groove with collar taper angle of $9^{\circ}$, corner radius of $30 \mathrm{~mm}$ and groove depth of $63 \mathrm{~mm}$. The experimental rolling load was calculated by using different analytical models given in table 3. The rolling load is calculated by consideration of strain, strain rate, temperature and composition of the steel using Misaka's equation [21]. The mill current value for a given deformation strain was measured and was converted to the rolling torque. The final rolled bar was allowed to cool in air to room temperature. The macrostructure and microstructure were analysed at various sections of the hot rolled bar. The macrostructure of the billet was obtained by etching in $35 \%$ hydrochloric acid and the microstructure was examined by etching with $5 \%$ nital. The microstructure samples were examined under Zeiss Axio-Tech optical microscope with Axiovision analyser software. 
Table 3. Analytical models used for the calculation of the rolling load.

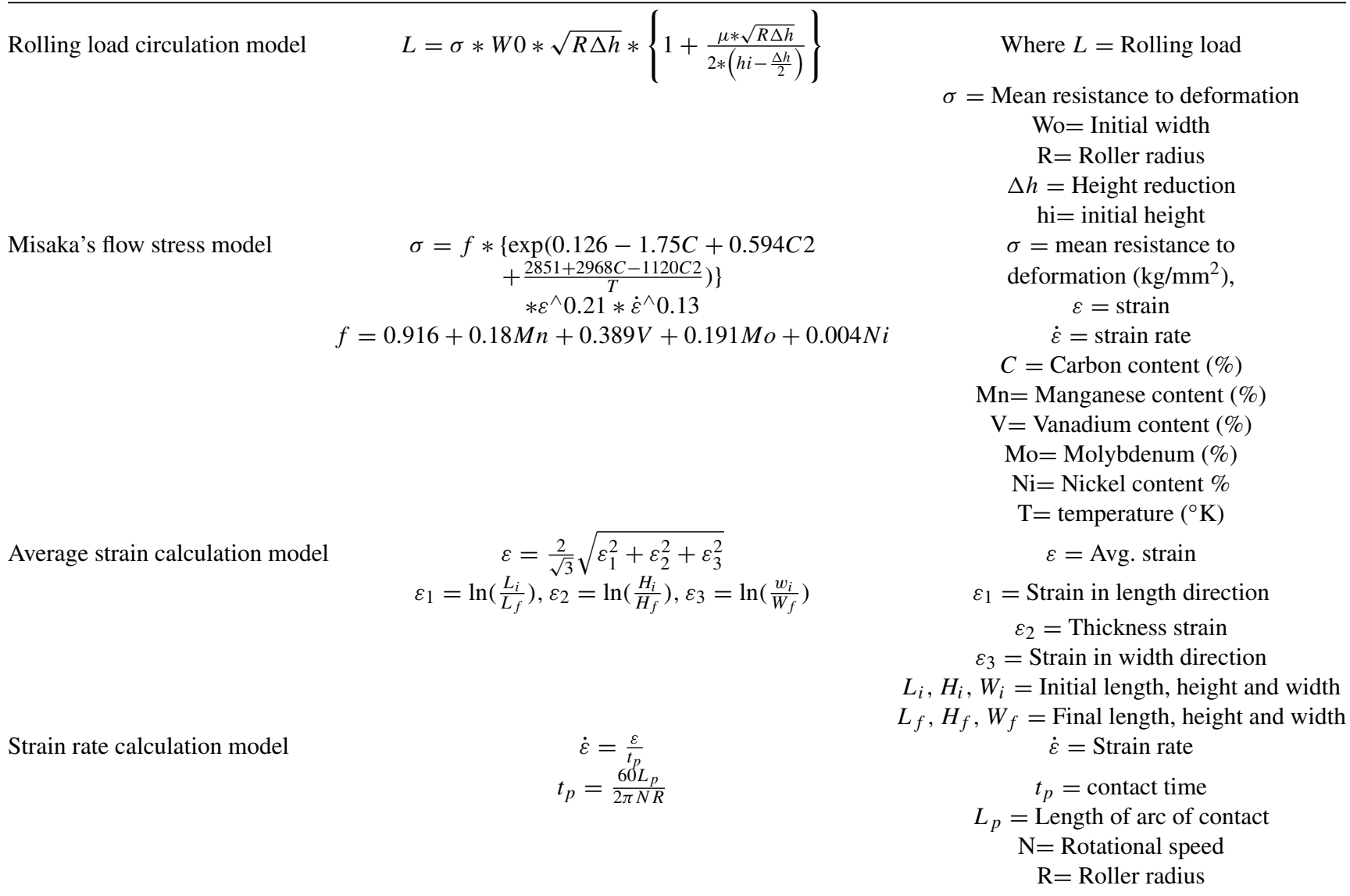

\section{Results and discussion}

The investigation is focused on assessing the influence of initial roll pass sequence in a break down mill with varied drafting schedule in a two-high reversible rolling mill. In every pass, if the maximum deformation suitable to the mill load capacity is achieved then the internal quality and productivity would increase. In steel plants, a wide range of product cross sections have to be manufactured and hence there are different grooves in a single roller with varying internal geometry. In addition, the formability of the work piece material decides the extent of deformation. Hence, an optimum deformation strain and strain rate is maintained during rolling. Highest deformation may not be possible in every pass as there could be problems of restriction of mill load and fin formation due to restriction of the groove width. Very high deformation also produces excessive heat that may deteriorate the microstructure. In the present study, the effect of changing the deformation strain during hot rolling in the initial passes on the metal flow behaviour in a typical single groove has been examined

In any hot rolling process the material at the surface layer tends to flow more than the bulk leading to fish tail formation. This fish tail formation starts increasing with

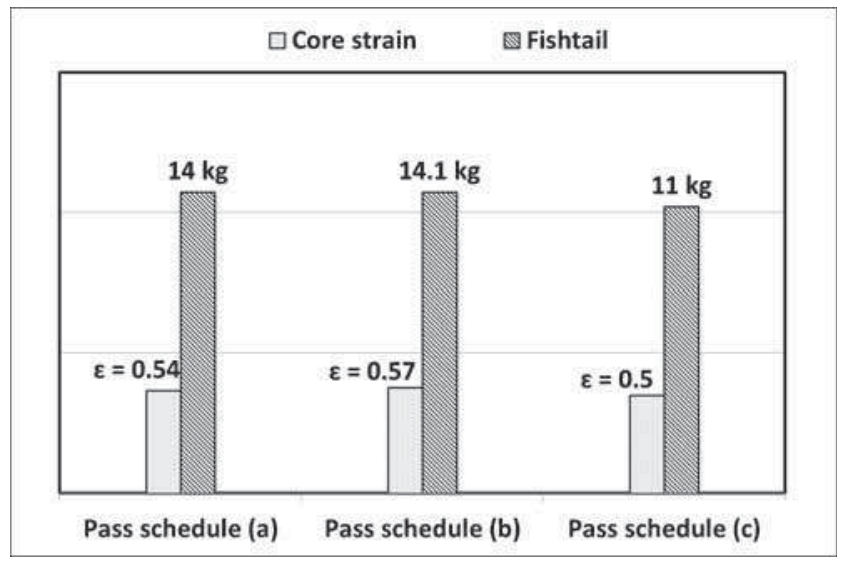

Figure 5. The effective strain at core and amount of end crop loss due to fishtail formation with the rolling pass sequences (a), (b) and (c) (table 2). (Roll groove with collar taper angle of $9^{\circ}$, corner radius of $30 \mathrm{~mm}$ and groove depth of $63 \mathrm{~mm}$ ).

reduced strain per pass or increasing the number of passes. The minimisation of the fish tail formation has a direct influence on the yield of the material. The present study examines the formation of fish tail and associated material yield. 


\subsection{Influence of roll pass schedules on deformation behaviour}

The effect of deformation strain per pass and pass sequence on the deformation behaviour is important in order to design the proper rolling pass schedule. The pass schedule should be designed in such a way that, it ensures good deformation of the material in every pass with proper utilization of the mill capacity. It has to also deliver better quality products by achieving higher strain penetration, improvement of yield and product without defects. The present study establishes the metal flow behaviour in the rolling of the steel bloom in a single groove through three different pass schedules (a), (b)

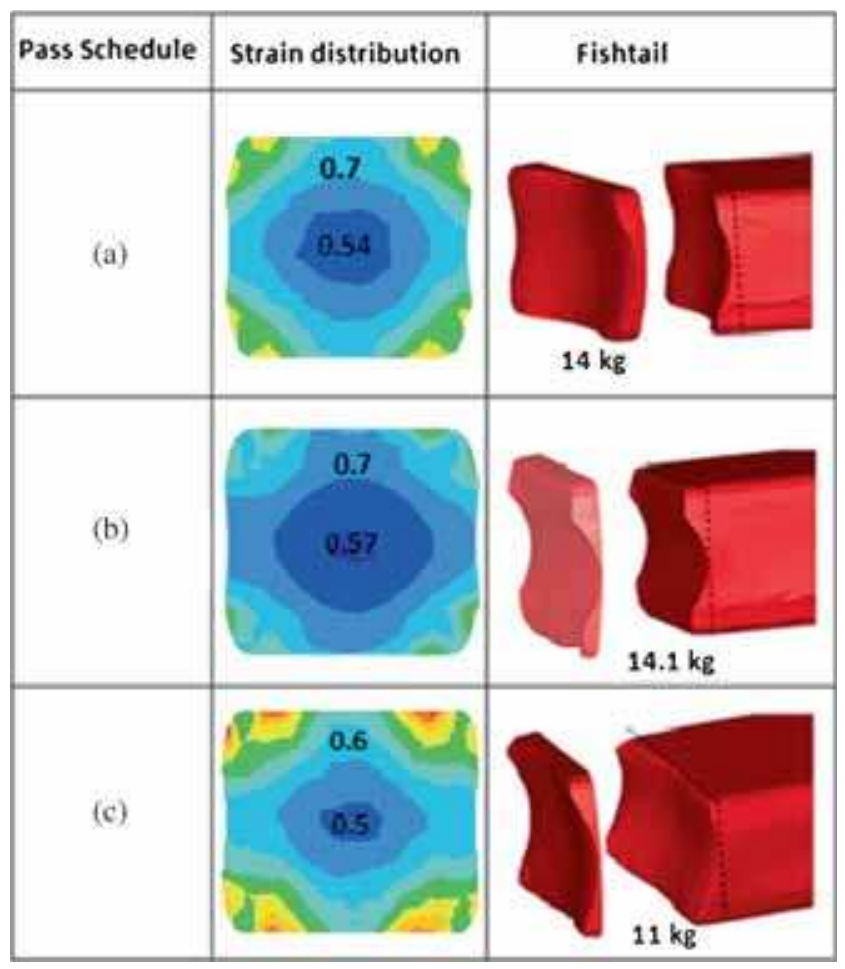

Figure 6. Effect of pass schedule on strain distribution on rolled material cross section and fishtail (roll groove with collar taper angle of $9^{\circ}$, corner radius of $30 \mathrm{~mm}$ and groove depth of $63 \mathrm{~mm}$ ). and (c) as shown in table 2 The variation in core strain and the fish tail formed in each of the pass schedule is shown in figure 5 and figure 6 .

It is seen that the pass schedule (a) (table 2) gave an effective strain of 0.54 at the core and with a fish tail loss of $14 \mathrm{~kg}$. This pass schedule has lighter deformation strain per pass and an overall $31 \%$ deformation strain. The pass schedule (b) (table 2) shows highest effective strain of 0.57 in the core Although the deformation strain is $24 \%$ the fish tail loss is $14.1 \mathrm{~kg}$. The pass schedule (c) with highest deformation strain of $32 \%$ shows an effective strain of 0.5 but the fish tail loss is $11 \mathrm{~kg}$. Thus, it could be realised that modification of roll pass schedule can affect the strain penetration and the fish tail formation.

The pass schedule (a) has two forward passes and two reverse passes. The forward pass has higher deformation strain compared to reverse pass. This is followed by a $90^{\circ}$ tilt and the next two passes follow a pattern similar to the first two passes. From figure 6 it can be seen that the strain variation from the surface to centre is more. This leads to non-uniform metal deformation along the cross section. The strain is concentrated on the surface and the highest fish tail

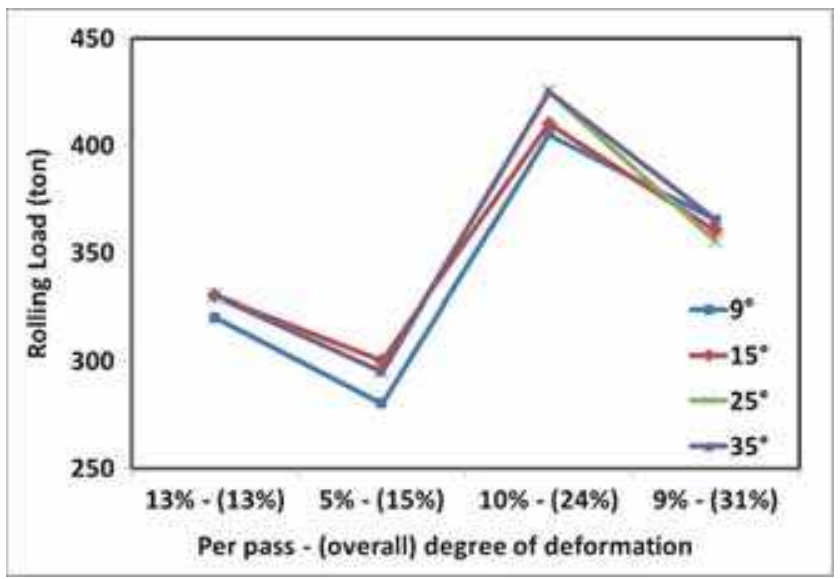

Figure 8. Variation of rolling load with respect to deformation strain at different collar taper angles (roll groove with corner radius of $30 \mathrm{~mm}$ and groove depth of $63 \mathrm{~mm}$ ).

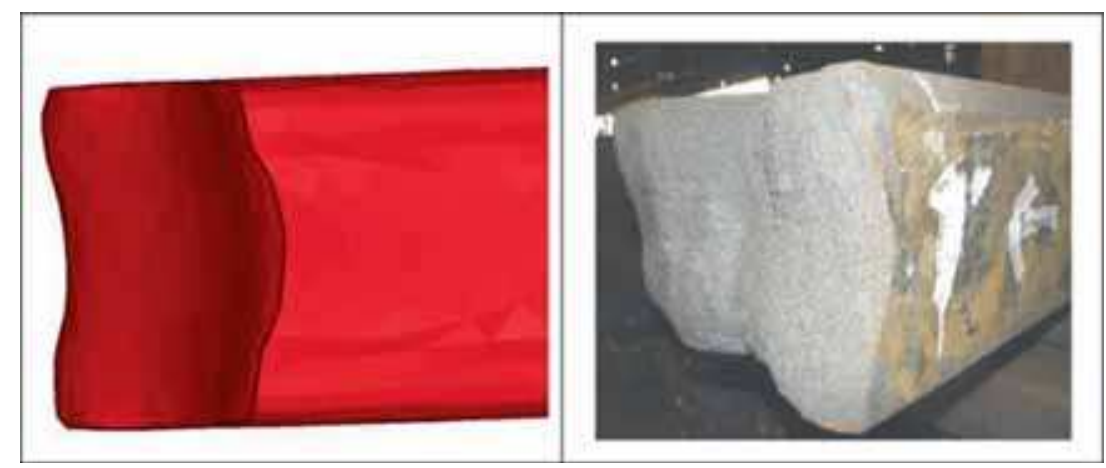

Figure 7. Comparison of the fish tail observed in simulation and actual experimentation after fourth pass of rolling using pass schedule (a) (roll groove with collar taper angle of $9^{\circ}$, corner radius of $30 \mathrm{~mm}$ and groove depth of $63 \mathrm{~mm}$ ). 
loss was observed in this case The pass schedule (b) has $18 \%$ deformation strain in the forward pass and $7.5 \%$ deformation degree in reverse pass without a tilt. In other words good deformation on one side of the bloom with a total deformation strain of $24 \%$ resulted in good strain penetration in the core but a higher fish tail formation. In this pass schedule higher strain in the reverse pass is limited by the groove width and the associated fin formation due to overfilling. The pass schedule requires higher mill load as well.

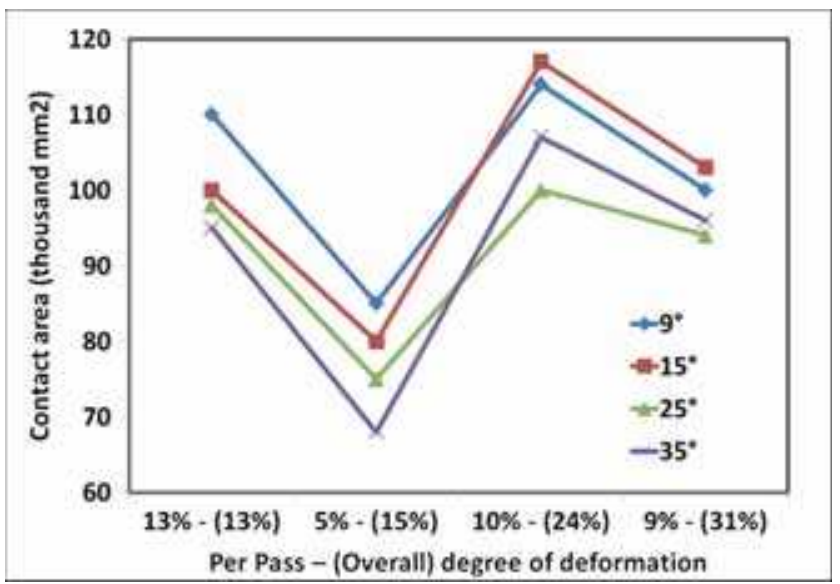

Figure 9. Contact area between bloom and roller with respect to deformation strain at different collar taper angles (roll groove with corner radius of $30 \mathrm{~mm}$ and groove depth of $63 \mathrm{~mm}$ ).
To overcome the problem due to excess width spread by reducing the bloom without tilt, the pass schedule (c) was evaluated. It has $18 \%$ deformation strain in forward pass followed by a $90^{\circ}$ tilt and $19 \%$ deformation strain in the reverse pass. The mill load is effectively utilised within the two passes. Due to heavier reduction in both the passes, the core strain has a value of 0.5 Since, the deformation has taken place uniformly in both the sides of the bloom the fish tail formation is lowered by $25 \%$ as compared to the fish tail in pass schedules (a) and (b) However, such a pass schedule may be difficult in some of the reversible mills as the tilt has to be carried out with poorer operator visibility on the opposite side.

The deformation in the first two to four passes as above shows that pass schedules (b) and (c) use higher capacity of the mill load. Higher deformation especially in the initial hot bloom ensures higher effective strain in core which results in healing of the core porosity in a cast bloom, and effective breakage of the cast structure. The reduction in the number of passes due to higher draft conserves the energy in the billet and also improves productivity. Hence, roll pass designs have to take advantage of the means to achieve the highest deformation strain possible, especially in the initial stages. However, the draft should match with the adiabatic rise in temperature, which should be matched with the rolling speed.

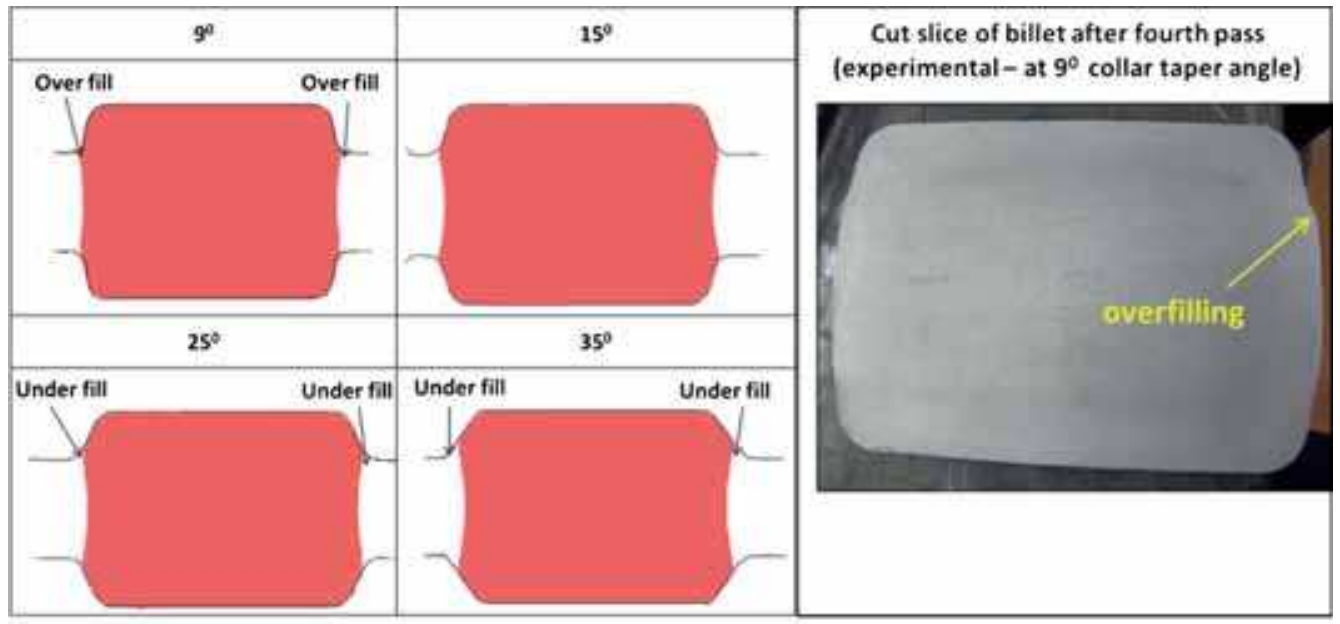

(a)

(b)
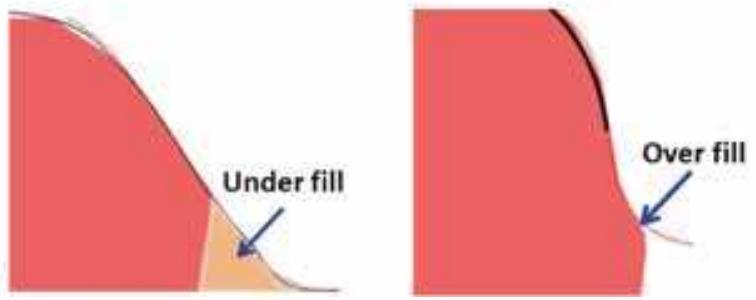

Figure 10. (a) Metal fill within the roll groove during fourth pass of rolling at different collar taper angle (roll groove with corner radius of $30 \mathrm{~mm}$ and groove depth of $63 \mathrm{~mm}$ ). (b) Typical under-fill where the billet does not fill groove cavity along the sidewalls and over-fill in the groove the billet bulges out of the groove side wall. 


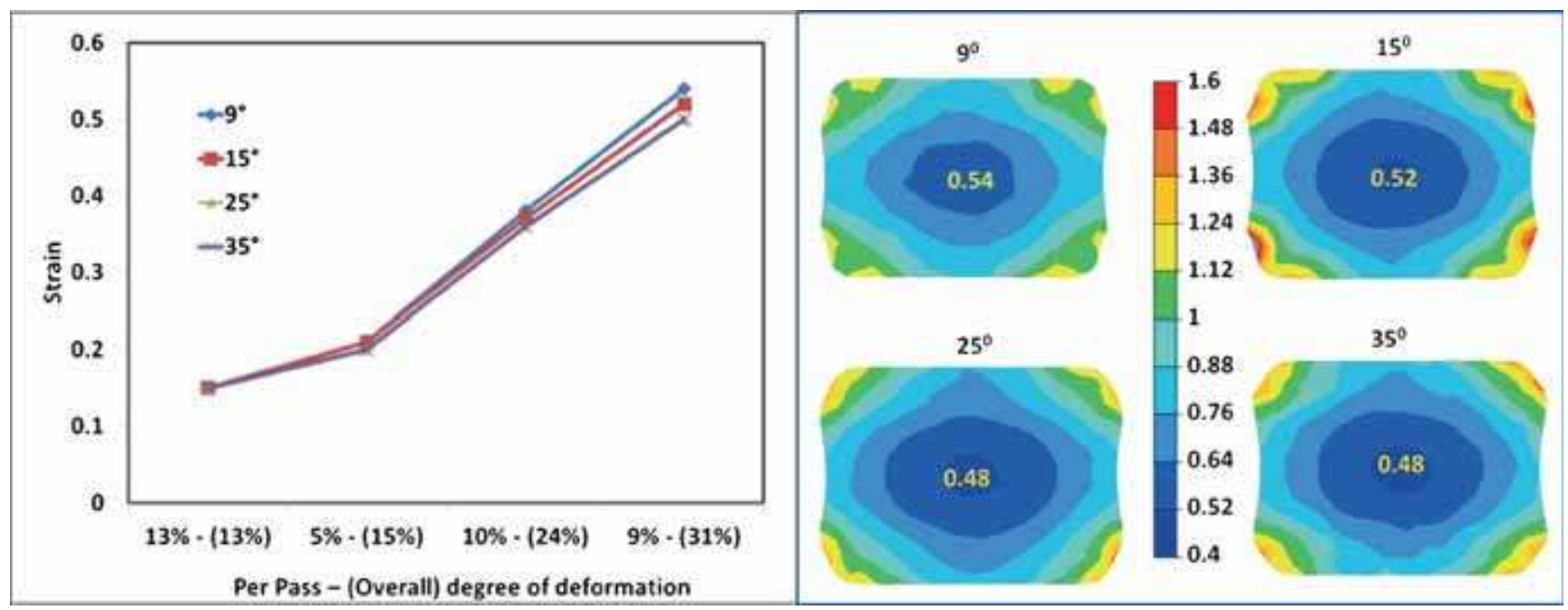

Figure 11. Core strain with respect to deformation strain, collar taper angle and strain distribution across the cross section after fourth pass at different collar taper angles (roll groove with corner radius of $30 \mathrm{~mm}$ and groove depth of $63 \mathrm{~mm}$ ).

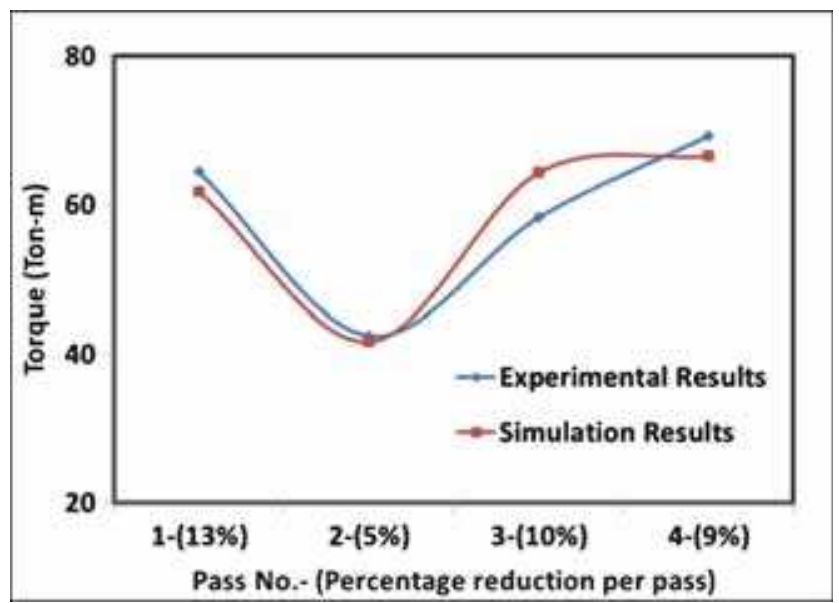

Figure 12. Comparison of simulated and experimental results for torque during different passes of rolling shows approximately similar trend in both cases. (Roll groove with collar taper angle of $9^{\circ}$, corner radius of $30 \mathrm{~mm}$ and groove depth of $63 \mathrm{~mm}$ ).

The simulation results of hot rolling the bloom as per pass schedule (a) was matched with experimental results for the rolling load, torque, macrostructure (strain penetration), microstructure and end shape (fish tail). The fishtail shape formed after the rolling of the bloom in the initial four passes in the simulation and the experiment showed a close match as in figure 7 . The fish tail observed by simulation was found to be $14 \mathrm{~kg}$ while the rolled bar showed a value of $18 \mathrm{~kg}$.

\subsection{Influence of collar taper angle on metal deformation}

Proper design of the collar taper angle of a roller groove leads to better metal flow within the pass minimizes the mill load, avoidance of defects like overlap and fins. The taper

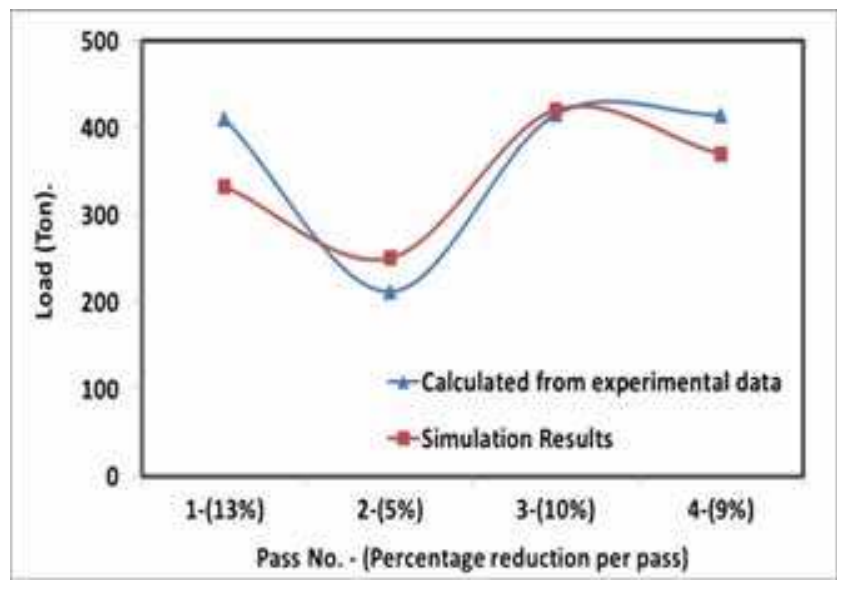

Figure 13. Comparison of simulated and experimental results for mill load produced during different passes of rolling, shows approximately similar trend in both cases. (Roll groove with collar taper angle of $9^{\circ}$, corner radius $30 \mathrm{~mm}$ and groove depth $63 \mathrm{~mm}$ ).

permits free entry and delivery of the stock accommodating the width spread of material in the groove, which results in smooth flow of the metal. Generally, the collar angle for a roughing mill groove is maintained between $9^{\circ}$ and $20^{\circ}$ [1] The frictional losses due to higher metal flow in the pass can be minimized by designing proper collar taper angle. Hence, in the present study, simulation was carried out at the collar taper angles of $9^{\circ}, 15^{\circ}, 25^{\circ}$ and $35^{\circ}$ using a pass schedule (a) as shown in table 2 .

The rolling load with respect to the deformation strain for the different collar taper angle is shown in figure 8 . The load distribution after the first forward pass of $13 \%$ with different collar taper angle shows a load value varying between 320 and 340 tons. The load at $9^{\circ}$ collar angle is lower, while the load at $15^{\circ}$ and $25^{\circ}$ is equal and higher. In the reverse pass, the reduction per pass is just $5 \%$ and the load value 
is lower varying between 280 and 305 tons. Similar trend is observed in the second pass. In the third forward pass after a $90^{\circ}$ tilt and at $10 \%$ reduction per pass, the load increases to values between 405 and 425 tons. The collar angles $9^{\circ}$ and $15^{\circ}$ take a lower limit of the load and the higher angles take the upper load limit. The load increase in the third pass may be attributed to the higher input thickness, larger reduction and strain hardening of the steel. In the fourth reverse pass with $9 \%$ deformation strain, the load value ranges between 355 and 365 tons. The load observed in the case of $9^{\circ}$ collar angle shows higher value than other collar angle. The load exerted in a groove is dependent on the contact area of the bloom and the roller. During the initial three passes, the load observed in the case of $9^{\circ}$ collar angle is less as compared to $15^{\circ}, 25^{\circ}$ and $35^{\circ}$. This can be justified by the highest contact area between the bloom and the roller, which results in lowering the rolling pressure and load as in figure 9. In the fourth pass, the load observed is more in case of $9^{\circ}$ collar angle due to the overfilling of the pass. The experimentally rolled billet cut after the fourth pass was correlated with simulation results, where overfilling behaviour was observed as shown in figure 10(a) and (b). There is no complete pass filling in the case of $25^{\circ}$ and $35^{\circ}$ collar angle figure $10(\mathrm{~b})$.

The effective strain at the core during each rolling pass for the different collar angles is shown in figure 11. With increasing deformation the effective strain increased with all taper angles. Higher strain was seen with $9^{\circ}$ angle, probably due to the higher restriction of the metal within the pass. Thus, the lower collar taper angle of the groove ensures

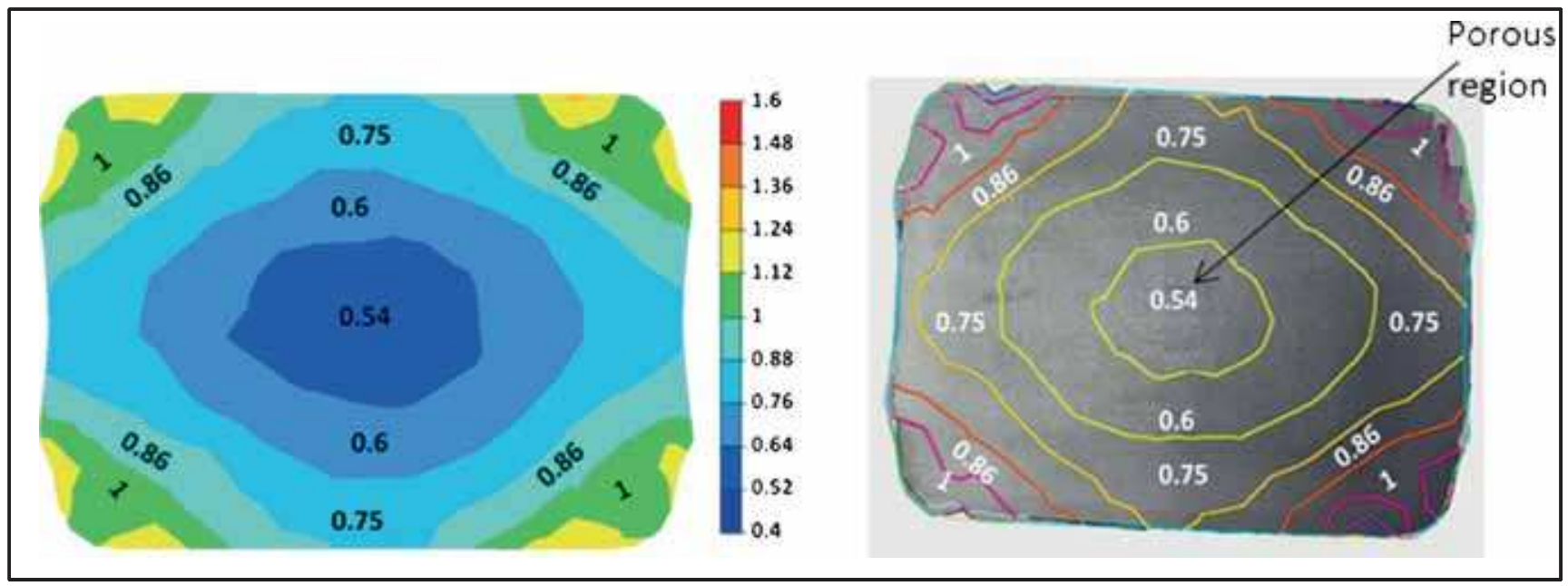

Figure 14. Superimposition of simulation results of strain contours on actual slice of rolled bar after fourth pass of rolling $\left(9^{\circ}\right.$ collar taper angle, R30 corner radius and $63 \mathrm{~mm}$ depth of pass) shows porous region at the centre of the bar due to the lower strain.

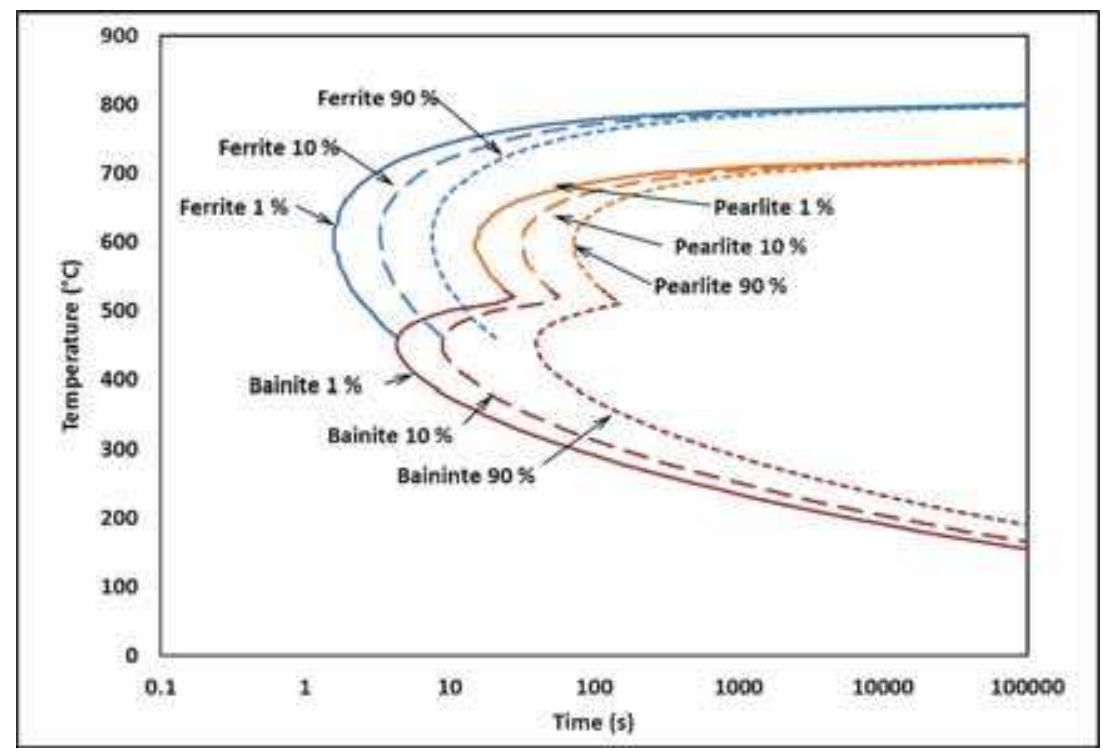

Figure 15. TTT diagram of $38 \mathrm{MnSiV} 5$ [22]. 


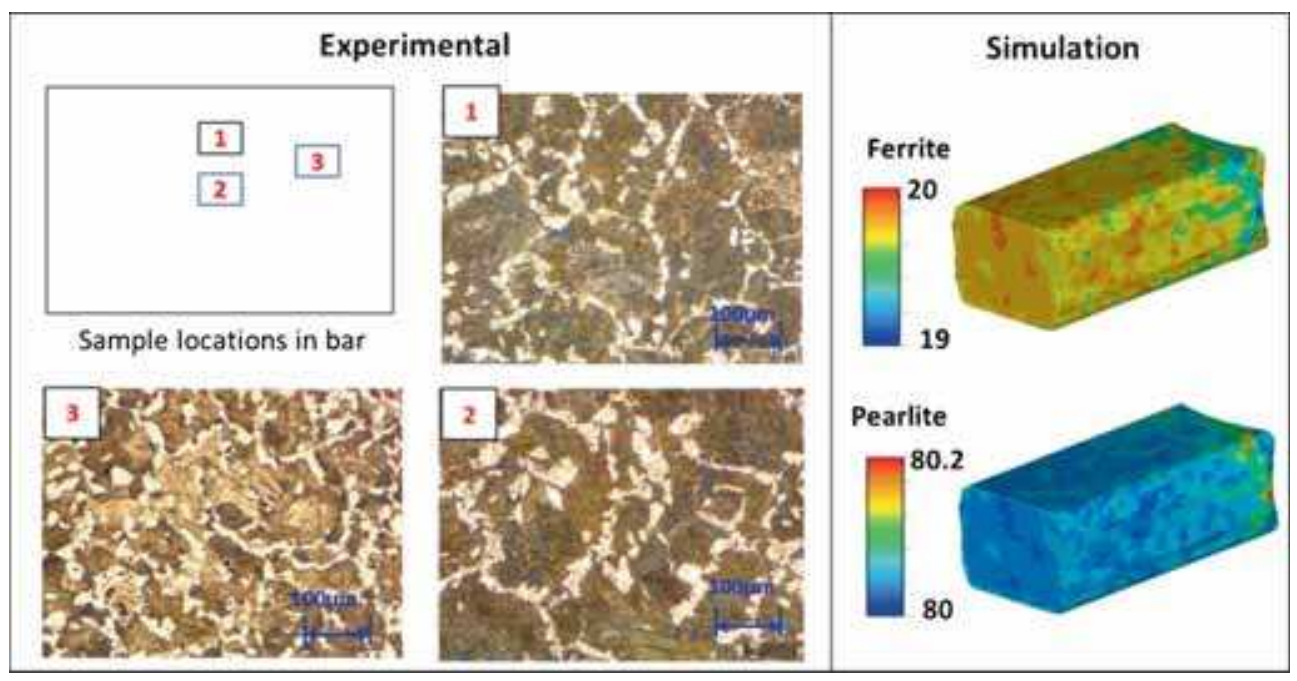

Figure 16. Experimental and simulation result of microstructural investigations shows phase distribution (roll groove with collar taper angle of $9^{\circ}$, corner radius of $30 \mathrm{~mm}$ and groove depth of $63 \mathrm{~mm}$ ).

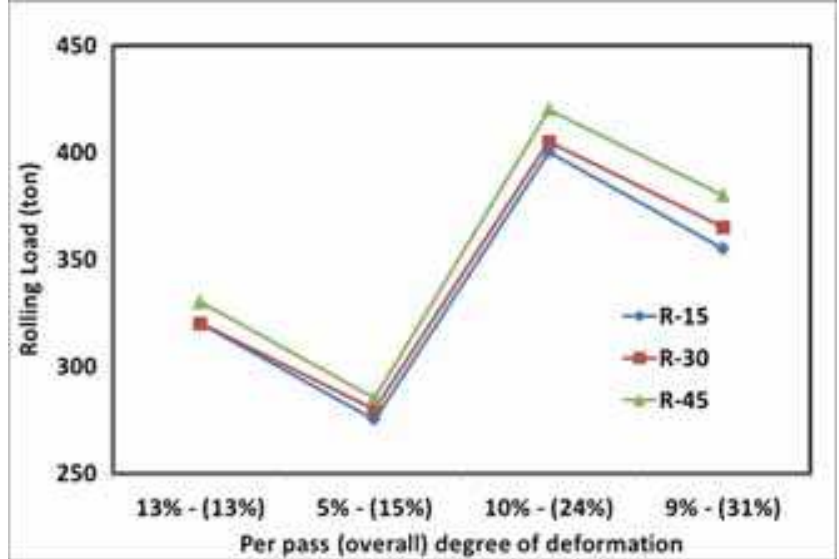

Figure 17. Rolling load as a function of the deformation strain at different corner radius (roll groove with collar taper angle of $9^{\circ}$ and groove depth of $63 \mathrm{~mm})$.

higher deformation penetration and lower loads during deformation.

Using the experimentally measured rolling mill motor current values, the rolling torque was calculated and validated with simulation as shown in figure 12. The torque values of the experimental and simulation results show similar trend in both cases with small variation. This small variation may be attributed to the deviations in the measured current value, which could be due to fluctuation of current values caused by thermal gradient in the bar [9]. The analytical and predicted results from simulation of rolling load during the different rolling passes are shown in figure 13 .

The strain contours obtained from the simulation was superimposed with the macrographs of rolled billet after fourth pass as shown in figure 14. The amount of strain between each bounded region is shown in figure 14. The super imposed result clearly shows that the central regions

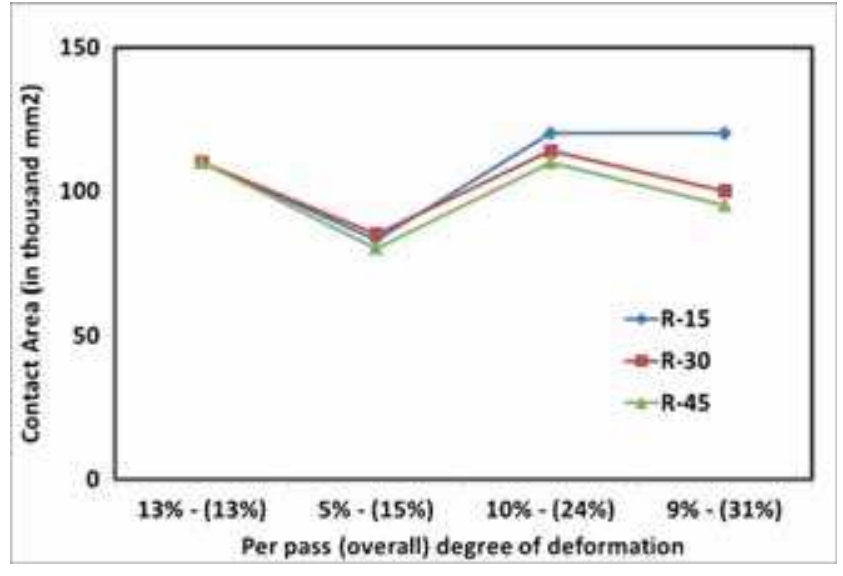

Figure 18. Contact area as a function of the deformation strain at different corner radius (roll groove with collar taper angle of $9^{\circ}$ and groove depth of $63 \mathrm{~mm}$ ).

with lower strain values are less consolidated as evidenced from darker porosity spots. The surface region with higher strain shows dense recrystallized structure.

Analysis was carried out on the ability of the model to predict the microstructure in terms of percentage of phases after the fourth pass of rolling. In both the experimental and simulation evaluations, the final rolled bar was allowed to cool in normal air up to the room temperature. The simulated microstructure at various location of the billet was based on super imposition of the cooling rates on the TTT-diagram (figure 15) in the model. The experimental analysis of the microstructure at various locations of the billet showed about $16-18 \%$ of pro-eutectoid ferrite in a pearlite matrix, while the predicted microstructure showed a pro-eutectoid ferrite of $19-20 \%$ in pearlitic matrix as shown in figure 16 . In the present study, only a limited number of passes have been considered to assess the capability of the model to 
predict and the accuracy of the results. The model can be extended for the entire pass schedule chosen. In addition, if multi-stand rolling is considered, it is possible to assess the grain structure evolution by incorporation of the dynamic and metadynamic recrystallization that takes place during the deformation and interpass duration. The recrystallization equation based on Zener Holloman parameters is available for the present steel grade [23].

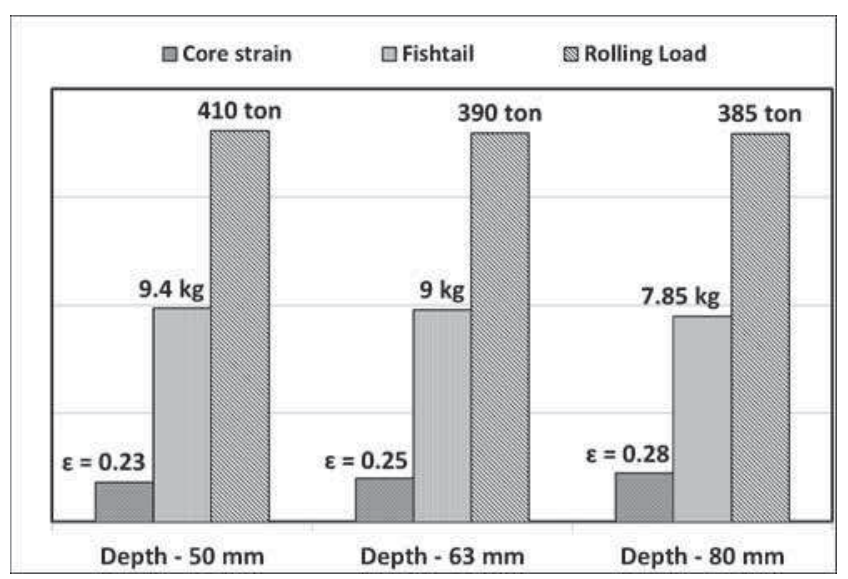

Figure 19. Core strain, end cut weight due to fishtail and rolling load variation with different groove depths (roll groove with collar taper angle of $9^{\circ}$ and corner radius $30 \mathrm{~mm}$ ).

\subsection{Influence of corner radius on deformation behaviour}

In order to understand, the effect of corner radius of a grooved pass on the metal flow behaviour within the pass, rolling simulations were carried out with varying corner radius. In this case, the variation of the mill load with respect to the deformation strain was studied with rolling pass schedule (a) as shown in table 2 . Three different corner radius of curvature R15, R30 and R45 was considered. The dependence of load per pass on the deformation strain for the three radii of curvatures is shown in figure 17 . The rolling load in each pass is found to increase with the radius of curvature. The load requirement is found to be less in the case of corner radius $\mathrm{R} 15$, which may be attributed to the more surface contact area as shown in figure 18. The experimental results of the rolling load, torque, macrostructure and microstructure in a groove dimension of R30 at $63 \mathrm{~mm}$ draft and $9^{\circ}$ collar taper angle was validated with model results as shown in figures 12-15.

\subsection{Influence of groove depth on metal deformation}

The effective roll radius is one of the factors, which influences the roll separating force and the flow of the material within the pass. In the case of grooved rollers, the effective roller radius depends on the depth of the groove. Generally, the depth of a groove pass is maintained less than a

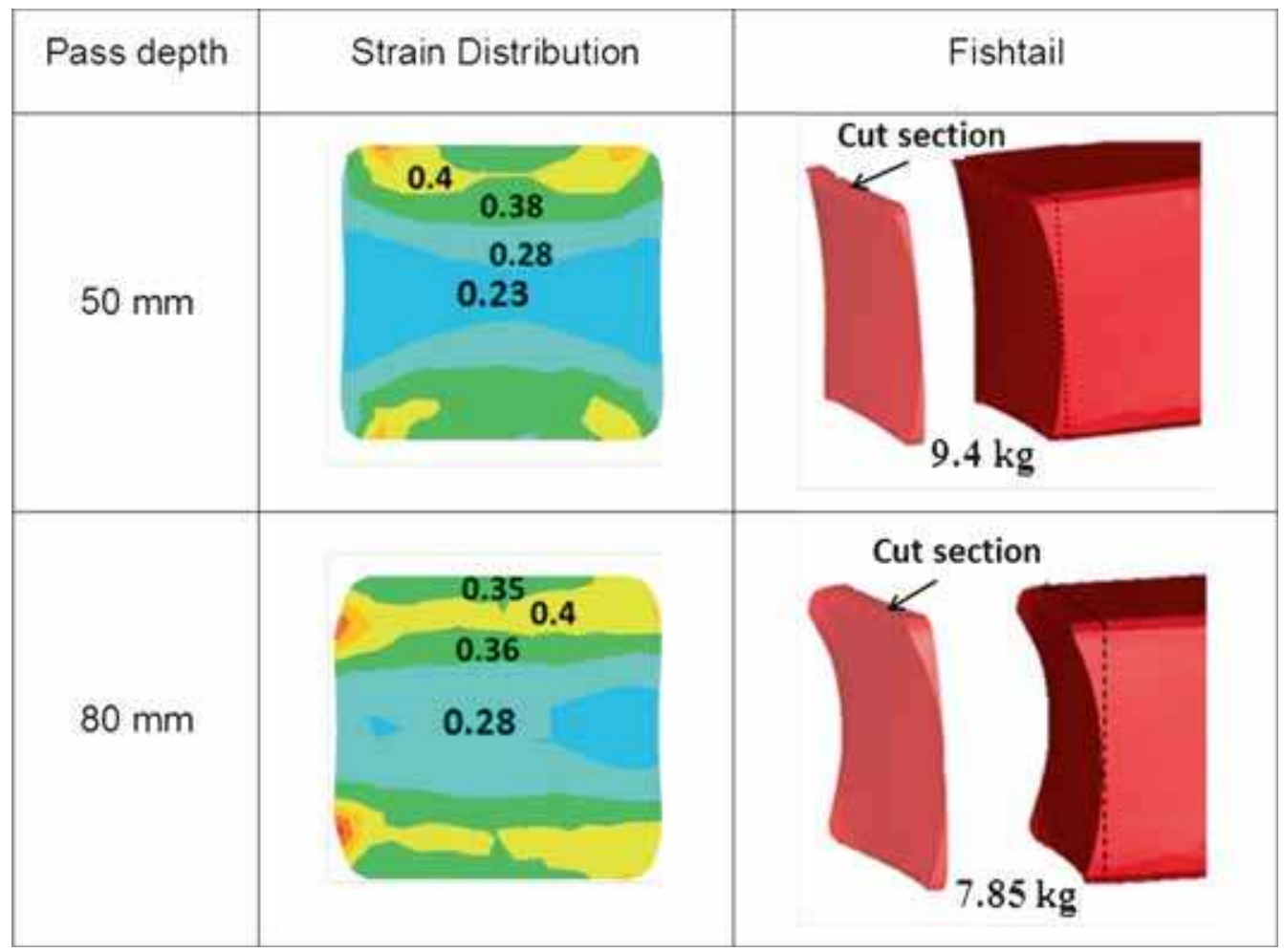

Figure 20. Strain distribution and end cut due to fishtail formation after rolling through grooved pass with varying pass depth (roll groove with collar taper angle of $9^{\circ}$ and corner radius $30 \mathrm{~mm}$ ). 
sixth of the roller diameter Single pass rolling at three different groove depths $(50 \mathrm{~mm}, 63 \mathrm{~mm}$ and $80 \mathrm{~mm})$ was simulated and compared with the experimental mill load and macrostructure The comparison of the core strain penetration, end cut weight loss due to fishtail formation and the rolling load in all the three cases is shown in figure 19. The results show that the core strain penetration increases with increase in the groove depth. This is probably due to more restriction in the width spread in a deeper groove which increases the surface contact area between the roller and the bloom. The rolling load is found to significantly decrease with increasing groove depth. The larger groove depth constrains the metal flow within the pass and ensures better strain penetration at the centre which further reduces the fishtail formation as well. The fishtail at each end was about $9.4 \mathrm{~kg}$ (i.e. yield loss of $0.54 \%$ ) in the case of smaller pass depth of $50 \mathrm{~mm}$ and $7.05 \mathrm{~kg}$ (i.e. yield loss of $0.40 \%$ ) with the larger pass depth of $80 \mathrm{~mm}$ as shown in figure 20 . The increase in groove depth can improve the degree of deformation which results in improved strain penetration, reduction in rolling load and reduced fishtail formation. But, increasing the groove depth may lead to temperature loss, more wear, more frictional power loss and reduced service life of the rolls.

In summary, the metal flow behaviour as a function of groove geometry and pass schedule in a blooming mill was established using FEM model and validated by typical experimental results. Lower collar taper angle, lower corner radius and higher depth of groove in hot rolling enable achievement of higher strain penetration, optimum mill load and lower fish tail formation. The model is capable of predicting the load, torque and microstructure. This sort of analysis enables to virtually foresee the quality of the steel and achieve optimum conditions for maximising yield and productivity of the mill.

\section{Conclusion}

- The metal flow behaviour, strain distribution, temperature distribution, mill load, microstructure was predicted in the hot rolling of 38MnVS6 steel bar using Forge FEM simulation software. The effect of pass schedule for the initial few passes, and the roll groove geometry parameters were examined.

- The investigation examined three different pass schedules to achieve the same reduction in the initial few passes. It was observed that light drafts with higher number of passes leads to lower effective strain and gave more fish tail formation. Increasing the draft on same side of the billet to achieve the same reduction gave higher strain penetration, higher load and larger fish tail formation. Higher draft with single tilt gave better strain penetration with lower fish tail formation and with higher mill productivity.
- The effect of groove collar taper angle showed that the lowest collar taper angle of $9^{\circ}$ gave lowest load, with desired groove filling. The load is higher for collar angle up to $35^{\circ}$. The effect of groove depth showed that higher groove depth gave better strain penetration with lower mill load and lower fish tail formation. The effect of groove corner radii showed that the load increases with increase in corner radius.

- The result obtained in the simulation was validated in an experimental groove and good correlation was obtained between the simulated groove geometry and the experimental groove. The simulation predicted the rolling load, strain penetration, microstructure, and fish tail formation at various stages and this was found to show good match with experimental investigation. Thus, the FEM based simulation could be successfully applied for arriving at the roll groove design and pass schedule during hot rolling.

\section{References}

[1] Wasatowski Z 1969 Fundamentals of rolling 1st ed., Pergamon Press, pp. 25-150

[2] Mori K, Osakada K and Oda T 1982 Simulation of planestrain rolling by the rigid plastic finite element method. Int. J. Mech. Sci. 24: 519-527

[3] Robert W L 1983 Hot rolling of steel, 1st ed. Markel Dekker, pp. $1-50$

[4] Stahalberg U and Goransson A 1986 Heavy reduction by means of 'Non Bite rolling' including some observation on work piece shape. J. Mech. Working Technol. 12: 373-384

[5] Duan X and Sheppard T 2001 Prediction of temperature evolution by FEM during multi-pass hot flat rolling of aluminium alloys. Modelling Simulation Mater. Sci. Eng. 9: 525

[6] Biswas S, Joseph J, Gutierrez H and Kiefer B V 2003 Useroriented three-dimensional finite element modelling of high speed bar and rod rolling. In: Proceeding of 45th iron \& steel society mechanical working and steel processing conference

[7] Hong H, Kang Y, Feng C and Chen X 2003 Three dimensional thermo mechanical coupled FEM simulation for hot continuous rolling of large diameter mandrel bar. J. Mater. Sci. Technol. 19: 228-230

[8] Byon S M, Kim S I and Lee Y 2004 Predictions of roll force under heavy- reduction hot rolling using a large-deformation constitutive model. Proc. Inst. Mech. Eng. B 218: 483-494

[9] Mróz S, Jagieła K and Dyja H 2007 Determination of the energy and power parameters during groove-rolling. $J$. Achievement Mater. Manuf. Eng. 2: 59-62

[10] Stefanik A, Szota P and Dyja H 2009 Numerical modelling of the microstructure during $50 \times 20 \mathrm{MM}$ flat bars rolling process. Arch. Metall. Mater. 54: 589-596

[11] Motallebi S R 2010 Investigation of influence parameters on the hot rolling process using finite element method. In: Proceeding of 2 nd international conference on engineering optimization, pp. 332-338

[12] Tomas Kubina, Miroslav Kucera and Rostislav Kocur 2010 Mathematical simulation of bar rolling with refined friction coefficient. Rožnov pod Radhoštěm, Česká Republika 
[13] Shevchenko D V, Saraev D Y, Nesterenko D L and Borovkov AI 2011 FEM study of metal rolling in grooved rolls. In: Proceedings of the 8th European LS-DYNA users conference

[14] Licheng Y, Jinchen J, Jinxiang H and Liwei N 2011 Prediction of process parameters on stress and strain field in hot rolling process using finite element method. Inf. Technol. J. 10: 24062412

[15] Nalawade R S, Date P P, Mahadik K N and Cheekatla V S K 2011 Control of end defect on rolled bar. Proceedings of the International Conference on Technology of Plasticity, pp. 61-66

[16] Nalawade R S, Date P P, Mahadik K N, Cheekatla V S K, Balasubramanian V and Singh R 2012 A novel method to reduce end crop loss on rolled bars. Steel Tech. J. 6: 5766

[17] Xuetong Li, Lei Cao, Minting Wang and Fengshan Du 2012 Groove design and microstructure research of ultra-fine grain bar rolling. Model. Numer. Simul. Mater. Sci. 2: 67-75

[18] Nalawade R S, Puranik A J, Balachandran G, Mahadik K N and Balasubramanian V 2013 Simulation of hot rolling deformation at intermediate passes and its industrial validity. Int. J. Mech. Sci. 77: 8-16
[19] Aksenov S A, Chumachenko E N, Logashina I V and Kubina T 2015 Numerical simulation in roll pass design for bar rolling. Metalurgija 54: 75-78

[20] British Steel Corporation 1975 Roll pass design. Chorley \& Pickersgill Ltd., pp. 20-70

[21] Manohar P, Kyuhwan L, Rollett A D and Lee Y 2003 Computational exploration of microstructural evolution in a medium C-Mn steel and applications to rod mill. ISIJ Int. 43: 14211430

[22] Werke M, Kristoffersen H, Haglund S, Svensson L and Nord A 2008 Predicting residual stresses and hardness of a critical component using a combination of numerical and empirical methods. Steel Res. Int. J. ISSN 1611-3683, 2: 812819

[23] Sen-dong G, Li-wen Zhang, Jin-hua R, Ping-zhen $Z$ and Yu Z 2014 Constitutive modelling of dynamic recrystallization behaviour and processing map of 38MnVS6 non-quenched steel. J. Mater. Eng. Performance 23: 10621068

[24] Hadasik E, Jedrusik D and Kawalla R 2004 Comparison of the flow stress functions determined in the hot compression and torsion tests. Acta Metall Slovaca 10: 271-278 